\title{
Recovery from community acquired pneumonia: the view from the top of the iceberg
}

\author{
Grant Waterer ${ }^{1,2}$ \\ Affiliations: ${ }^{1}$ University of Western Australia, Perth, Australia. ${ }^{2}$ Northwestern University, Chicago, IL, USA.
}

Correspondence: Grant Waterer, Level 4 MRF Building, Royal Perth Hospital, GPO Box X2213, Perth 6847 , Australia. E-mail: grant.waterer@uwa.edu.au

@ERSpublications

Recovery from pneumonia is much more complicated than the paper in this issue of the ERJ suggests http://ow.ly/1UlC30bFNLS

Cite this article as: Waterer G. Recovery from community acquired pneumonia: the view from the top of the iceberg. Eur Respir J 2017; 49: 1700571 [https://doi.org/10.1183/13993003.00571-2017].

A very common question patients with pneumonia ask is, "When will I be better?" My usual response is a mixture of educated guess and anecdotal experience: "Probably not for 6-8 weeks at least - and it may be longer", mentally reducing that time frame for younger patients and increasing it for the elderly. Given how fundamentally important this question is for our patients, the study in this issue of the journal by WооттоN et al. [1] is particularly welcome. What I am not sure of is whether the study conducted has really answered the question.

WootTon et al. [1] used serial recording of the community-acquired pneumonia (CAP) symptom questionnaire (CAP-sym) [2] to estimate the average time to recovery of symptoms in 169 patients. The major conclusions of the study are that most patients will return to their pre-pneumonia baseline, with 97\% of symptoms resolving within 10 days (mean 9.8 days, 95\% CI 7.3-12.2 days). The CAP-sym measures 18 symptoms including coughing, chest pains, shortness of breath and fatigue [2].

How then do we reconcile an apparent resolution of symptoms in an average of 10 days with substantial evidence that survivors of CAP have significantly worse health outcomes over the subsequent months to years? [3-11]. Are the findings of WoOTTON et al. [1] generally representative of patients with CAP elsewhere? Is the "new" pathology driving the adverse outcomes truly unrelated to the speed and completeness of resolution of pneumonia, or are we not measuring resolution properly?

There are clues in other studies, many with disparate results. MARRIE et al. [12] studied 535 patients and found that at 6 weeks, $64 \%$ of patients still reported at least one CAP-related symptom. EL MoussaOui et al. [13] studied 102 adults with mild-to-moderate pneumonia (pneumonia severity index grade I-III [14]) using a different symptom questionnaire to the CAP-sym and found that although respiratory symptoms typically resolved within 14 days, symptoms of well-being resolved much more slowly, taking up to 6 months. Furthermore the persistence of symptoms beyond 28 days was attributed to underlying comorbid conditions, not the pneumonia itself. MetLaY et al. [15] studied 576 patients with CAP and found that over 50\% of patients still reported fatigue at 90 days. BRUNs et al. [16] compared the resolution of radiological findings, clinical findings and patient symptoms. They found that by day 28 , while radiology had resolved in $68 \%$ of patients and clinical signs had resolved in $89 \%$, symptoms were completely resolved in only $42 \%$ of patients. Not surprisingly, it appears that patients who have more severe initial symptoms take longer to recover [17].

Received: March 192017 | Accepted: March 202017

Conflict of interest: None declared.

Copyright @ERS 2017 
Age is clearly a critical factor in the speed and completeness of recovery from CAP. EL SolH et al. [18] studied 301 patients with CAP and a mean age of 74 years. They found that over one-third of patients had impaired physical function at discharge, with $11 \%$ still being impaired at 3 months. Premorbid cognitive decline and comorbidities were key predictors of impaired functional recovery. Radiological resolution is also greatly prolonged in older age groups, with $40 \%$ of patients aged 70 years or older having incomplete resolution at 6 weeks, and $15 \%$ at 12 weeks [19]. The presence of chronic obstructive pulmonary disease (COPD) in particular appears to be associated with longer recovery times from pneumonia [20], and smokers have a slower resolution of radiological changes than nonsmokers [21].

It is also possible that the infecting pathogen may play a role in determining the speed of recovery. BRANDENBURG et al. [22] found that in 158 patients with pneumococcal pneumonia, symptoms frequently persisted at 30 days, with more than $50 \%$ of patients still experiencing cough and dyspnoea and $48 \%$ still producing sputum at that time point. In contrast, the resolution of symptoms from CAP due to mycoplasma infection appears to be faster, although one in eight patients still has symptoms at 42 days [23].

How do we interpret the very significant range of results in these studies? Clearly fever resolves quite quickly, while it is unusual for cough and pleuritic pain to persist for longer than 2 weeks. Sputum production and dyspnoea (at rest or during activities of daily living) also usually resolve within 2 weeks. What is much more difficult to establish, but fundamentally much more important, is when patients truly return to their baseline health status and their former physical and cognitive function. It is likely that different findings in the studies described above are due to differences in the patients' age range and prior comorbid disease status, and in the wording and style of the questionnaire used. Differences in cultural and social acceptance of chronic symptoms may also be a factor [24-26].

While not established, it is reasonable to hypothesise that those who take longest to recover are those at greatest risk of long-term adverse health outcomes. Even small elevations of systemic inflammatory markers such as C-reactive protein have been associated with substantial increases in subsequent cardiac events $[27,28]$, and patients with the highest level of inflammatory markers at discharge from hospital with CAP have the worst 1-year outcomes [29]. The persistence of radiological infiltrates for months in some patients suggests a continued low-level inflammatory response. As has been established with exacerbations of COPD [30], some patients may not ever recover to their baseline function after an episode of CAP. Reduced physical activity is associated with higher cardiovascular disease risk [31], while increased physical activity has a systemic anti-inflammatory effect [32]. Any impairment of exercise function due to incomplete recovery from CAP, even if patients are not aware of it, may be critical.

To really answer the question of "When will I be better?", we need much more detailed studies of CAP survivors using highly objective tools. This will certainly include actigraphy to track physical activity, serial neurocognitive assessment and some measure of systemic inflammatory response. Since some CAP survivors continue to have worse health outcomes than population controls for years afterwards, for some the truthful answer may be "Never". However, being able to accurately determine a "healthy" recovery profile from an "unhealthy" one will be a significant leap forward in designing, testing and implementing interventions to improve the long-term health outcomes of patients who have had pneumonia.

\section{References}

1 Wootton DG, Dickinson L, Pertinez H, et al. A longitudinal modelling study estimates acute symptoms of community acquired pneumonia recover to baseline by 10 days. Eur Respir J 2017; 49: 1602170.

2 Lamping DL, Schroter S, Marquis $\mathrm{P}$, et al. The community-acquired pneumonia symptom questionnaire: a new, patient-based outcome measure to evaluate symptoms in patients with community-acquired pneumonia. Chest 2002; 122: 920-929.

3 Mortensen EM, Kapoor WN, Chang CC, et al. Assessment of mortality after long-term follow-up of patients with community-acquired pneumonia. Clin Infect Dis 2003; 37: 1617-1624.

4 Waterer GW, Kessler LA, Wunderink RG. Medium-term survival after hospitalization with community-acquired pneumonia. Am J Respir Crit Care Med 2004; 169: 910-914.

5 Corrales-Medina VF, Alvarez KN, Weissfeld LA, et al. Association between hospitalization for pneumonia and subsequent risk of cardiovascular disease. JAMA 2015; 313: 264-274.

6 Alan M, Grolimund E, Kutz A, et al. Clinical risk scores and blood biomarkers as predictors of long-term outcome in patients with community-acquired pneumonia: a 6-year prospective follow-up study. J Intern Med 2015; 278: 174-184.

7 Sandvall B, Rueda AM, Musher DM. Long-term survival following pneumococcal pneumonia. Clin Infect Dis 2013; 56: 1145-1146.

8 Bruns AH, Oosterheert JJ, Cucciolillo MC, et al. Cause-specific long-term mortality rates in patients recovered from community-acquired pneumonia as compared with the general Dutch population. Clin Microbiol Infect 2011; 17: 763-768.

9 Johnstone J, Eurich DT, Majumdar SR, et al. Long-term morbidity and mortality after hospitalization with community-acquired pneumonia: a population-based cohort study. Medicine (Baltimore) 2008; 87: 329-334.

10 Eurich DT, Marrie TJ, Minhas-Sandhu JK, et al. Ten-year mortality after community-acquired pneumonia. A prospective cohort. Am J Respir Crit Care Med 2015; 192: 597-604. 
11 Shah FA, Pike F, Alvarez K, et al. Bidirectional relationship between cognitive function and pneumonia. Am J Respir Crit Care Med 2013; 188: 586-592.

12 Marrie TJ, Lau CY, Wheeler SL, et al. Predictors of symptom resolution in patients with community-acquired pneumonia. Clin Infect Dis 2000; 31: 1362-1367.

13 El Moussaoui R, Opmeer BC, de Borgie CA, et al. Long-term symptom recovery and health-related quality of life in patients with mild-to-moderate-severe community-acquired pneumonia. Chest 2006; 130: 1165-1172.

14 Fine MJ, Auble TE, Yealy DM, et al. A prediction rule to identify low-risk patients with community-acquired pneumonia. N Engl J Med 1997; 336: 243-250.

15 Metlay JP, Fine MJ, Schulz R, et al. Measuring symptomatic and functional recovery in patients with community-acquired pneumonia. J Gen Intern Med 1997; 12: 423-430.

16 Bruns AH, Oosterheert JJ, El Moussaoui R, et al. Pneumonia recovery: discrepancies in perspectives of the radiologist, physician and patient. J Gen Intern Med 2010; 25: 203-206.

17 Marrie TJ, Beecroft MD, Herman-Gnjidic Z. Resolution of symptoms in patients with community-acquired pneumonia treated on an ambulatory basis. J Infect 2004; 49: 302-309.

18 El Solh A, Pineda L, Bouquin P, et al. Determinants of short and long term functional recovery after hospitalization for community-acquired pneumonia in the elderly: role of inflammatory markers. BMC Geriatr 2006; 6: 12.

19 El Solh AA, Aquilina AT, Gunen H, et al. Radiographic resolution of community-acquired bacterial pneumonia in the elderly. J Am Geriatr Soc 2004; 52: 224-229.

20 Wyrwich KW, Yu H, Sato R, et al. Observational longitudinal study of symptom burden and time for recovery from community-acquired pneumonia reported by older adults surveyed nationwide using the CAP Burden of Illness Questionnaire. Patient Relat Outcome Meas 2015; 6: 215-223.

21 Mittl RL Jr, Schwab RJ, Duchin JS, et al. Radiographic resolution of community-acquired pneumonia. Am J Respir Crit Care Med 1994; 149: 630-635.

22 Brandenburg JA, Marrie TJ, Coley CM, et al. Clinical presentation, processes and outcomes of care for patients with pneumococcal pneumonia. J Gen Intern Med 2000; 15: 638-646.

23 Marrie TJ, Beecroft M, Herman-Gnjidic Z, et al. Symptom resolution in patients with Mycoplasma pneumoniae pneumonia. Can Respir J 2004; 11: 573-577.

24 Sievert LL, Anderson D, Melby MK, et al. Methods used in cross-cultural comparisons of somatic symptoms and their determinants. Maturitas 2011; 70: 127-134.

25 Chesla CA, Skaff MM, Bartz RJ, et al. Differences in personal models among Latinos and European Americans: implications for clinical care. Diabetes Care 2000; 23: 1780-1785.

26 Alonso J, Black C, Norregaard JC, et al. Cross-cultural differences in the reporting of global functional capacity: an example in cataract patients. Med Care 1998; 36: 868-878.

27 Pischon T, Mohlig M, Hoffmann K, et al. Comparison of relative and attributable risk of myocardial infarction and stroke according to C-reactive protein and low-density lipoprotein cholesterol levels. Eur J Epidemiol 2007; 22: $429-438$.

28 Ahmadi-Abhari S, Luben RN, Wareham NJ, et al. Seventeen year risk of all-cause and cause-specific mortality associated with C-reactive protein, fibrinogen and leukocyte count in men and women: the EPIC-Norfolk study. Eur J Epidemiol 2013; 28: 541-550.

29 Yende S, D’Angelo G, Kellum JA, et al. Inflammatory markers at hospital discharge predict subsequent mortality after pneumonia and sepsis. Am J Respir Crit Care Med 2008; 177: 1242-1247.

30 Spencer S, Calverley PM, Burge PS, et al. Impact of preventing exacerbations on deterioration of health status in COPD. Eur Respir J 2004; 23: 698-702.

31 Myers J, McAuley P, Lavie CJ, et al. Physical activity and cardiorespiratory fitness as major markers of cardiovascular risk: their independent and interwoven importance to health status. Prog Cardiovasc Dis 2015; 57: 306-314.

32 Santos RV, Viana VA, Boscolo RA, et al. Moderate exercise training modulates cytokine profile and sleep in elderly people. Cytokine 2012; 60: 731-735. 